\title{
FREQUENCY ANALYSIS OF HUMAN JAW TREMOR AT REST
}

\author{
S. PALla and M. M. Ash, JR. \\ Stomatognathic Laboratory, Department of Occlusion, Dental Research Institute, \\ School of Dentistry, University of Michigan., Ann Arbor, MI 48109, U.S.A
}

\begin{abstract}
Summary-It is not known whether rest position is controlled actively by a low degree of muscular activity or passively by muscular and tissue visco-elasticity. The frequency analysis of the jaw tremor at rest was studied to determine if it could be useful for the study of rest position. Jaw tremor was recorded in three different head positions of normal subjects by two accelerometers fixed to the upper and lower premolars. The acceleration signals were low-pass filtered, digitized and analysed by computer. A Fast Fourier Transform algorithm was used to determine spectral density. Electromyograms of the right and left anterior temporal and masseter muscles and an electrocardingram were recorded with surface electrodes, and the data correlated with jaw tremor. The lower jaw oscillated at the same frequency as the head, and the tremor was a low-frequency narrow-band process. Head deflection produced changes in the power spectral density of the tremor. A time correlation between the shape of the acceleration raw data and the heart beat was present in every subject. However, frequency content and power spectral density of the jaw tremor at rest may be determined also by the degree of muscular activity.
\end{abstract}

\section{INTRODUCTION}

Normal postural tremor is the small involuntary oscillation of a limb or body part around a relatively constant mean position. Since the observations of Lippold, Redfearn and Vuco (1957), who discovered a burst of motor unit activity firing at the same frequency as the tremor, the possibility that the tremor is of neuromuscular origin has been widely investigated. Lippold (1970) stated that tremor of normal voluntary muscular contraction represents an oscillation in the stretch reflex servo loop. Elble and Randall (1976), using techniques for analysis of random signals, showed an association between the $8-12 \mathrm{~Hz}$ component of the finger tremor and an $8-12 \mathrm{~Hz}$ amplitude variation in the surface electromyogram (EMG) of the extensor digitorum. They thought a Renshaw inhibition-rebound mechanism is responsible for determining the tremor frequency. Stiles and Randall (1967) reported that finger tremor frequency increases with increased muscle contraction. Brumlik, (1962), Ozaki et al. (1962), Yap and Boshes (1967) and Carrie and Bickford (1969) claimed that the finger tremor is a cardio-ballistic phenomenon.

There is conflicting evidence as to whether the rest position of the mandible is maintained by low muscular activity (Møller, 1966; Lous, Sheikoleslam and Moller, 1970; Lund, Nishiyama and Moller, 1970; Moller, Sheikoleslam and Lous, 1971) or passively, by muscle and tissue elasticity (Yemm and Berry, 1969; Lynn and Yemm, 1971; Yemm and Nordstrom, 1974) owing to the difficulty in interpreting the electromyogram found at the clinical rest position or the EMG resting range (Garnick and Ramfjord, 1962) because of the low level of activity and the presence of electrical noise. Yemm (1976) concluded that the methods used to record activity from the jaw muscles of relaxed human subjects in mandibular rest position provide an inadequate basis for objective conclusions.
Although the mechanisms responsible for keeping the finger horizontal are probably different from those responsible for the rest position of the mandible, the above described findings on finger tremor suggest that analysis of the jaw tremor could help us understand the rest position.

Our objectives were (1) to define the frequency spectrum of the jaw tremor both at rest and with the head tilted forwards and hackwards by computing the tremor's spectral density function (Bendat and Piersol, 1971, p. 22), (2) to study the influence of cardiac activity on the tremor and (3) to investigate possible variations of the tremor-frequency spectra in terms of degree of muscular activity in the elevator muscles. The spectral density function describes the frequency composition and provides a reliable method to define tremor quantitatively.

\section{MATERIALS AND METHODS}

\section{Preliminary considerations}

We treated jaw tremor as a random mechanical vibration and chose to measure and analyse the variable of jaw tremor acceleration. Small, sensitive accelerometers which respond to extremely small oscillations were used because they ignore, better than distance-measuring devices, the bigger but slower position changes of the mandible which occur at rest (Bando et al., 1972; Joniot, 1974; Griffiths, 1975).

As the rest position is an equilibrium easily altered (Wyke, 1974), we did not fix the head for the tremor recordings. We attached a second accelerometer to the upper jaw to determine if lower jaw tremor could be head tremor transmitted through the mandible and if so, which frequency component it was. Subtracting the signal of the upper accelerometer from that of the lower one gives the acceleration of the lower jaw relative to the head. 


\section{Clinical procedure}

We studied 10 (6 male, 4 female) subjects, 22-33 years of age, with natural dentition, no history of disturbances of the masticatory system (Helkimo, 1974) and no headache or ear symptoms.

The 2 accelerometers recording tremor from the upper and lower jaw were cemented with Durelon cement to the labial surface of the upper and lower right premolars, the sensitive axis vertical, with the teeth tightly clenched. We checked visually that the accelerometers were parallel.

Muscle activity was monitored by recording the electromyographic (EMG) signals from the right and left anterior temporal and the right masseter muscles using bipolar silver or gold surface electrodes (Grass E4G and E4S) placed $2 \mathrm{~cm}$ apart in the direction of the muscle fibres after scrubbing the skin with alcohol. Commercial electrode jelly and adhesive collars attached the electrodes to the skin, the position heing determined by direct muscle palpation. The earth electrode was attached to the right ear lobe. We recorded the electrocardiogram (ECG) using surface electrodes (Grass E4G and E4S), attaching the differential electrodes to the left wrist and the left ear lobe. The earth electrode was the same as used for the EMG.

The subject sat upright in a dental chair in a Faraday room. Jaw tremor, ECG and EMG were recorded in the following sequence: (1) with head upright (Camper plane horizontal); (2) with head tilted backwards (Camper plane $+20^{\circ}$ ); (3) with head tilted forwards (Camper plane $-20^{\circ}$ ). The position of the Camper plane was controlled visually with a modified goniometer before each recording. The subject was instructed to close the eyes, to relax and to keep the mandible at rest during each procedure. The presence of an inter-occlusal space was checked but not measured before and after each recording. During the recording, the subject was alone, with the light off and the door closed. A 2-3 min adaptation period preceded each session. For each recording sequence we collected data over a period of at least $2 \mathrm{~min}$.

\section{Jaw tremor recording}

Figure 1 shows the data acquisition system. Jaw tremor was recorded by 2 damped strain-gauge simple-axis accelerometers (Entran-Egal 125-10D and 5D; Entran Devices, Little Falls, N.Y.) with the following specifications: weight $0.5 \mathrm{~g}$; size $6.8 \times 3.6 \times 3.6 \mathrm{~mm}$; sensitivity 10.0 and $10.4 \mathrm{mV} / \mathrm{g}$; range $\pm 10 \mathrm{~g}$ and $\pm 5 g$; frequency response flat from 2 to $100 \mathrm{~Hz}$; compensated temperature range $28-82^{\circ} \mathrm{C}$. The accelerometers were balanced (Incor bridge balance $1018 \mathrm{C}$ ) to provide 0 volts/direct current output when not mechanically excited. The noise level of the accelerometer and associated amplifier, measured with one accelerometer fixed to a table near the chair, was $1.62 \times 10^{-3} \mathrm{mV}$ root mean square (r.m.s.) equal to an r.m.s. acceleration of $1.62 \times 10^{-4} \mathrm{~g}$. The power spectral density of this signal had a peak at $27.20 \mathrm{~Hz}$. The acceleration signals were amplified by AC differential amplifiers (Grass 7P511) with the filters set to produce a flat frequency response from 3 to $280 \mathrm{~Hz}$ (accuracy within - 10 per cent; $-3 \mathrm{~dB}$ at $1.5 \mathrm{~Hz}$ ). The amplified signals were recorded on paper (Grass EEG Polygraph 78) and on magnetic tape (Hewlett-Packard 3955; band width of $0-1.25 \mathrm{kHz}$ ) and low pass filtered to $25 \mathrm{~Hz}$ (KrohnHite 3322).

The filtered analogue acceleration signals were converted into digits by an analogue-to-digital converter (Datel System 256) at a sampling ratio of $100,000 / \mathrm{s}$ (Geister, McCall and Ash, 1975). The noise introduced by digitization was $2.56 \mathrm{mV}$ r.m.s., equal to a maximum signal-to-noise ratio of about $50 \mathrm{~dB}$ (Brown, 1975). The digitized data were recorded on digital magnetic tape (Pertec 8840) (Geister et al., 1975).

We fed the low pass filtered signals into a differential amplifier (Dana 3520) before digitization to subtract the acceleration signal of the upper jaw from that of the lower one, giving the acceleration of the lower jaw relative to the head. The differential signal was digitized as described for the single signals. Because of the differentiation process, the sensitivity of the two accelerometers was equalized before each recording session. With the accelerometers taped to the empty dental chair, one amplifier (Grass 7P511) was adjusted until the differential signal displayed on the oscilloscope screen was as small as possible. The chair was chosen because it produces the same spectral character to both accelerometers in the frequency range $0-16 \mathrm{~Hz}$. We obtained the differential signal for 8 out of 10 subjects.

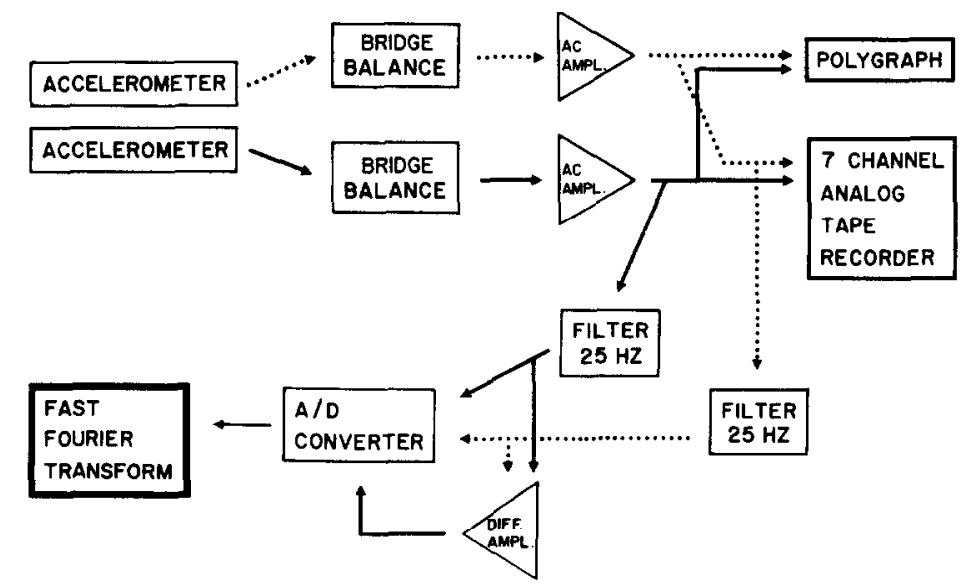

Fig. 1. Schematic diagram of the data acquisition system for jaw tremor acceleration. 
Data processing. The digitized data were displayed on the oscilloscope screen (Tektronik 4012) using an edit programme (Brown et al., 1979) to eliminate inaccurate data. We recorded the chosen portions on a new digital tape for subsequent frequency analysis by computer (AMDAHL 470V/6) and used a Fast Fourier Transform (FFT) algorithm (Harding, 1976) to obtain the power spectral density of the jaw tremor (frequency range $0-44.643 \mathrm{~Hz}$; resolution $0.17689 \mathrm{~Hz}$ ). The method was, except for the frequency range, similar to that used by Brown (1975) for the frequency analysis of EMG. We computed the power spectral density by averaging the results of the transforms of 15 samples of $5.6 \mathrm{~s}$ length each.

The power spectral density values were recorded on magnetic tape for further use, such as the computation of the cumulative power $[\mathrm{CP}(\mathrm{f})]$ and of the power spectra. The cumulative power tabulates frequency vs power density in per cent, being the total power at $44.643 \mathrm{~Hz} 100$ per cent. The power spectrum is the graphic display of the power spectral density. The horizontal axis represents the frequency and the vertical axis the power (mean square value of the amplitude in volts). The power spectra reproduced here do not allow a comparison between the power of the single signals and that of the differential signal because the power of the differential signal was amplified 4 or 25 times for plotting on the same scale.

As jaw tremor appears to be random, the true power spectral density can be calculated within some confidence interval from the estimated value. Randall and Stiles (1964) found that finger tremor has a Gaussian amplitude distribution. Using these findings and the fact that, for moderate deviation from Gaussian distribution, many statistical results show only slight errors (Mercer, 1958), we assumed that the powers estimators have a chi-squared distribution. The 95 per cent confidence limits for the true power were from 0.64 to 1.79 times the estimated power (Bendat and Piersol, 1971, p. 189). Thus, a peak-to-valley or peakto-peak ratio of approximately $2.8: 1$ was necessary for a peak value to be significant at the 95 per cent confidence interval. According to this, the frequency at maximum power spectral density $\left(F_{\text {mpsd }}\right)$ refers to the one at which the significant highest power occurred. When a significant higher power value was not present, all the frequencies having a power not differing significantly from the maximum power estimate were tabulated as $F_{\text {mpsd }}$. We also computed r.m.s. value, standard deviation and 95 per cent confidence intervals of the acceleration of the upper and lower jaw. The computation method was the same as used for the quantification of the EMG.

\section{Electromyography}

The EMG signals were amplified by AC differential amplifiers (Grass 7P511) with the filters set to produce a flat frequency response between 70 and $400 \mathrm{~Hz}$ (accuracy within -10 per cent; down $3 \mathrm{~dB}$ at 40 and $600 \mathrm{~Hz}$ ). The input noise measured with shorted electrodes was $0.7 \pm 0.13 \mu \mathrm{V}$ r.m.s. The amplified EMG analogue signals were recorded on paper, on magnetic tape, digitized and checked as described for the acceleration signals. A computer program provided mean r.m.s. value, standard deviation, and 95 per cent confidence intervals for the EMG signal of each muscle.
We computed the r.m.s. values from 30 record samples of $0.7 \mathrm{~s}$ each (1024 data points) distributed over a period of 1 minute, removing any baseline offset by subtracting the average value of the first record sample from the value of each data point.

\section{Jaw tremor and electrocardiography}

To detect any relationship between jaw tremor and heart activity, the acceleration signals were triggered between 5 and 20 times from the ECG-R-peak, respectively, at random points (Tektronik Time Base/ Ampl. $5810 \mathrm{~N}$ ) and stored on an oscilloscope screen. Polaroid prints were made for further analysis.

\section{Statistical analysis}

We checked $C P(f)$ values for statistically significant differences between upper and lower jaw tremor and for significant changes within the lower/upper jaw tremor at different head positions. We analysed the EMG-r.m.s. values for differences between the muscles as well as within the same muscle at different head positions, using the following non-parametric tests at the 0.05 significance level: Wilcoxon matchedpairs signed-rank test, Walsh test and Friedman test (Siegel, 1956).

\section{RESULTS}

Jaw tremor power spectral density

The results of the upper and lower jaw tremor are shown in Tables $1,2,3$ and 5 , and those of the differential signal in Table 4 . Figures 2 and 3 show typical power spectra. For all three head positions, the power spectral density of the upper and lower jaw tremor differed in the power but not in the frequency domain (Fig. 2), showing that the lower jaw oscillated at the same frequency as the head.

\section{Head upright (Camper plane at $0^{\circ}$ )}

The power spectra showed that for all 10 subjects the jaw tremor was a low-frequency narrow-band oscillatory process, being on average 90 per cent of the total power of the lower/upper jaw below 10.44/9.92 Hz (Tables 2 and 3). The 90 per cent value was below the filtering cut-off frequency, so the tremor signals did not contain significant frequency bands above approximately $10 \mathrm{~Hz}$. In all 10 subjects, the power spectra presented many spectral bands (peaks) (Figs. 2 and 3), suggesting that the rest tremor occurred at more than one principal frequency. Table 1 shows the values of the peak frequency for each significant frequency band $\left(F_{\text {mpsd }}\right)$ for all ten subjects. The group mean values for the lower/upper jaw tremor were $5.22 / 5.37 \mathrm{~Hz}$.

The lower and upper jaw tremor showed non-significant differences in the acceleration r.m.s. values. The r.m.s. acceleration of the lower jaw tremor ranged from $1.09 \times 10^{-3}$ to $2.58 \times 10^{-3} \mathrm{~g}$ (mean $1.75 \times 10^{-3} \mathrm{~g}$ ) and that of the upper jaw tremor from $1.02 \times 10^{-3}$ to $2.44 \times 10^{-3} \mathrm{~g}$ (mean $1.64 \times 10^{-3} \mathrm{~g}$ ).

The power spectra of the differential signal (lower minus upper jaw tremor acceleration) of 7 out of 8 subjects had the same general shape as that of the single signals (Fig. 3) but the tremor power was distributed in a wider frequency range than that of the single signals (Table 4). The group mean frequency 
Table 1. Frequency at the maximum power spectral density $\left(F_{\text {mpsd }}\right)$ of the lower jaw (l.j.) and upper jaw (u.j.) tremor measured in $\mathrm{Hz}$

\begin{tabular}{|c|c|c|c|c|c|c|}
\hline \multirow[b]{2}{*}{ Subject } & \multicolumn{2}{|c|}{$\begin{array}{c}\text { Head } \\
\text { upright }\left(0^{\circ}\right)\end{array}$} & \multicolumn{2}{|c|}{$\begin{array}{c}\text { Head } \\
\text { deflected }\left(+20^{\circ}\right)\end{array}$} & \multicolumn{2}{|c|}{$\begin{array}{c}\text { Head } \\
\text { flexed }\left(-20^{\circ}\right)\end{array}$} \\
\hline & $1 . j$ & u.j. & l.j. & u.j. & l.j. & u.j. \\
\hline \multirow[t]{3}{*}{ B.S. } & 4.71 & 6.98 & \multirow[t]{3}{*}{7.15} & \multirow[t]{3}{*}{7.15} & \multirow[t]{3}{*}{4.53} & 4.53 \\
\hline & 6.98 & 4.53 & & & & 6.80 \\
\hline & 3.49 & & & & & \\
\hline \multirow[t]{2}{*}{ C.P. } & 4.71 & 4.88 & \multirow[t]{2}{*}{7.15} & \multirow[t]{2}{*}{7.15} & 4.88 & 4.88 \\
\hline & & & & & 3.84 & 3.84 \\
\hline \multirow[t]{4}{*}{ H.S. } & 6.80 & 5.06 & \multirow[t]{4}{*}{6.45} & \multirow[t]{4}{*}{6.45} & 6.80 & 6.80 \\
\hline & 5.06 & 6.80 & & & 3.66 & 3.66 \\
\hline & 11.33 & 11.33 & & & 4.71 & 4.71 \\
\hline & & & & & 10.64 & 10.81 \\
\hline \multirow[t]{3}{*}{$\mathrm{Ha} . \mathrm{S}$. } & 6.98 & 6.98 & 3.84 & 3.84 & 7.85 & 7.85 \\
\hline & 3.49 & 3.49 & 6.45 & 6.45 & 4.88 & 10.46 \\
\hline & & & & 2.44 & 3.31 & 5.06 \\
\hline \multirow[t]{3}{*}{ L.J. } & 4.19 & 3.14 & 6.10 & 6.10 & 6.63 & 10.46 \\
\hline & 3.14 & 4.19 & 4.01 & 4.01 & 10.46 & 6.63 \\
\hline & & & & 2.96 & 4.19 & 5.23 \\
\hline \multirow[t]{4}{*}{ M.N. } & 4.36 & 4.36 & 6.63 & 4.19 & 3.14 & 4.19 \\
\hline & 3.31 & 3.31 & 4.19 & 6.63 & 4.19 & 6.28 \\
\hline & & & & & 6.28 & 3.14 \\
\hline & & & & & 0.70 & \\
\hline \multirow[t]{3}{*}{ P.M. } & 0.35 & 0.39 & 6.45 & 6.45 & 8.55 & 8.55 \\
\hline & 5.58 & 5.58 & & & 5.06 & 5.06 \\
\hline & 7.85 & 7.85 & & & & 10.46 \\
\hline \multirow[t]{2}{*}{ P.H. } & 6.10 & 6.10 & 6.45 & 6.45 & 5.75 & 5.75 \\
\hline & & & & & 9.94 & \\
\hline \multirow[t]{2}{*}{ R.S. } & 6.80 & 6.80 & 6.28 & 6.28 & 6.28 & 6.28 \\
\hline & 3.49 & 3.66 & & & & \\
\hline \multirow[t]{5}{*}{ S.C. } & 8.02 & 8.02 & 7.32 & 7.32 & 9.07 & 9.07 \\
\hline & 5.41 & 5.41 & 9.60 & 9.60 & & \\
\hline & 2.62 & 2.62 & & & & \\
\hline & & 10.64 & & & & \\
\hline & & 1.36 & & & & \\
\hline Mean & 5.22 & 5.37 & 6.29 & 5.84 & 5.88 & 6.54 \\
\hline \multirow[t]{2}{*}{ Range } & 0.35 & 0.39 & 3.84 & 2.44 & 0.70 & 3.14 \\
\hline & 11.33 & 11.33 & 9.60 & 9.60 & 10.64 & 10.81 \\
\hline
\end{tabular}

Table 2. Frequency values in $\mathrm{Hz}$ at the 10,50 and 90 per cent values of the cumulative power for the lower jaw tremor

\begin{tabular}{|c|c|c|c|c|c|c|c|c|c|}
\hline \multirow[b]{2}{*}{ Subject } & \multicolumn{3}{|c|}{$\begin{array}{c}10 \text { per cent } \\
\text { Camper plane }\end{array}$} & \multicolumn{3}{|c|}{$\begin{array}{c}50 \text { per cent } \\
\text { Camper plane }\end{array}$} & \multicolumn{3}{|c|}{$\begin{array}{l}90 \text { per cent } \\
\text { Camper plane }\end{array}$} \\
\hline & $0^{\circ}$ & $+20^{\circ}$ & $-20^{\circ}$ & $0^{\circ}$ & $+20^{\circ}$ & $-20^{\circ}$ & $0^{\circ}$ & $+20^{\circ}$ & $-20^{\circ}$ \\
\hline B.S. & 3.47 & 4.58 & 4.12 & 6.66 & 6.94 & 6.61 & 11.21 & 9.77 & 11.81 \\
\hline C.P. & 2.59 & 3.69 & 3.63 & 4.70 & 6.46 & 4.91 & 9.47 & 7.71 & 10.73 \\
\hline H.S. & 3.81 & 4.39 & 3.09 & 6.83 & 6.36 & 6.64 & 12.17 & 9.98 & 11.80 \\
\hline Ha.S. & 3.26 & 2.52 & 3.79 & 6.47 & 5.48 & 7.89 & 10.01 & 8.81 & 11.72 \\
\hline L.J. & 2.97 & 2.97 & 4.35 & 5.02 & 5.95 & 9.07 & 13.63 & 8.53 & 12.76 \\
\hline M.N. & 2.02 & 3.12 & 0.99 & 4.30 & 6.14 & 4.67 & 9.23 & 9.35 & 10.08 \\
\hline P.M. & 0.28 & 4.88 & 3.90 & 5.09 & 6.55 & 7.33 & 8.22 & 10.28 & 10.57 \\
\hline P.H. & 3.31 & 5.25 & 4.87 & 6.09 & 6.29 & 6.09 & 9.89 & 8.28 & 10.41 \\
\hline R.S. & 3.67 & 5.22 & 3.18 & 6.14 & 6.23 & 6.31 & 8.09 & 8.12 & 8.21 \\
\hline S.C. & 2.50 & 4.73 & 5.53 & 7.37 & 6.99 & 8.59 & 12.46 & 9.97 & 11.01 \\
\hline Mean & 2.79 & 4.14 & 3.75 & 5.87 & 6.34 & 6.81 & 10.44 & 9.08 & 10.91 \\
\hline
\end{tabular}

(1) and (2) $P<0.05$, (4) and (6) $P<0.05$, (8) and (9) $P<0.01$. 
Table 3. Frequency values in $\mathrm{Hz}$ at the 10,5 . and 90 per cent values of the cumulative power for the upper jaw tremor

\begin{tabular}{lcccccccrrr}
\hline & \multicolumn{3}{c}{$\begin{array}{c}\text { 10 per cent } \\
\text { Camper plane }\end{array}$} & \multicolumn{3}{c}{50 per cent } & \multicolumn{3}{c}{90 per cent } \\
Subject & $0^{\circ}$ & $+20^{\circ}$ & $-20^{\circ}$ & $0^{\circ}$ & $+20^{\circ}$ & $-20^{\circ}$ & \multicolumn{2}{c}{$\begin{array}{c}\text { Camper plane } \\
+20^{\circ}\end{array}$} & $-20^{\circ}$ \\
\hline B.S. & 3.09 & 5.05 & 2.87 & 5.47 & 6.97 & 6.61 & 10.00 & 9.39 & 11.81 \\
C.P. & 2.32 & 3.72 & 3.29 & 4.62 & 6.47 & 4.79 & 7.83 & 7.58 & 9.53 \\
H.S. & 3.72 & 4.68 & 3.18 & 6.83 & 6.42 & 6.70 & 12.17 & 10.11 & 11.74 \\
Ha.S. & 3.35 & 3.01 & 2.54 & 6.63 & 5.48 & 7.89 & 10.46 & 8.81 & 11.72 \\
L.J. & 3.04 & 3.61 & 4.14 & 4.98 & 6.14 & 6.85 & 12.12 & 9.23 & 10.78 \\
M.N. & 0.89 & 3.85 & 0.76 & 4.25 & 6.50 & 4.44 & 8.99 & 9.87 & 10.16 \\
P.M. & 0.27 & 4.83 & 3.59 & 4.67 & 6.56 & 7.04 & 8.03 & 9.24 & 10.10 \\
P.H. & 4.44 & 5.30 & 4.67 & 6.17 & 6.31 & 6.17 & 9.87 & 8.46 & 10.60 \\
R.S. & 3.62 & 5.19 & 3.15 & 6.13 & 6.23 & 6.30 & 8.00 & 8.00 & 8.07 \\
S.C. & 2.32 & 5.08 & 5.31 & 7.27 & 7.09 & 8.84 & 11.74 & 10.14 & 11.15 \\
Mean & 2.71 & 4.43 & 3.35 & 5.70 & 6.42 & 6.56 & 9.92 & 9.08 & 10.57 \\
\hline & $(1)$ & $(2)$ & $(3)$ & $(4)$ & $(5)$ & $(6)$ & $(7)$ & $(8)$ & $(9)$
\end{tabular}

(1) and (2) $P<0.01$, (2) and (3) $P<0.05$, (4) and (6) $P<0.01,(7)$ and (8) $P<0.05$,

(8) and (9) $P<0.01$.

Table 4. Frequency at maximum power spectral density $\left(F_{\text {mpsd }}\right)$ and 10,50 and 90 per cent values of the cumulative power spectrum for the differential signal for 8 subjects

\begin{tabular}{|c|c|c|c|c|c|c|}
\hline \multirow[b]{2}{*}{$F_{\text {mpsd }}$} & \multicolumn{4}{|c|}{ Head } & \multicolumn{2}{|c|}{ Flexed $\left(-20^{\circ}\right)$} \\
\hline & $\begin{array}{c}\text { Mean } \\
5.42\end{array}$ & $\begin{array}{c}\text { Range } \\
1.40-14.47\end{array}$ & $\begin{array}{c}\text { Mean } \\
4.91\end{array}$ & $\begin{array}{l}\text { Range } \\
1.22-10.81\end{array}$ & $\begin{array}{c}\text { Mean } \\
5.63\end{array}$ & $\begin{array}{c}\text { Range } \\
1.92-13.78\end{array}$ \\
\hline \multicolumn{7}{|c|}{$\begin{array}{l}\text { Cumulative } \\
\text { power } \\
\text { (per cent) }\end{array}$} \\
\hline 10 & 1.98 & $1.17-3.13$ & 2.05 & $1.29-2.74$ & 1.92 & $1.48-2.44$ \\
\hline 50 & 6.03 & $4.72-7.22$ & 5.40 & $3.69-7.02$ & 6.35 & $4.11-7.52$ \\
\hline 90 & 13.57 & $10.05-17.73$ & 12.33 & $7.29-16.12$ & 14.00 & $8.32-18.13$ \\
\hline
\end{tabular}

Table 5. Per cent of the total power in the $5-8 \mathrm{~Hz}$ band

\begin{tabular}{lcccc}
\hline & \multicolumn{2}{c}{$\begin{array}{c}\text { Lower jaw } \\
\text { Camper } \\
0^{\circ}\end{array}$} & $\begin{array}{c}\text { Upper jaw } \\
+20^{\circ}\end{array}$ & \multicolumn{2}{c}{$\begin{array}{c}\text { Camper } \\
0^{\circ}\end{array}$} & $\begin{array}{r}\text { plane } \\
+20^{\circ}\end{array}$ \\
\hline Bubject & & & & \\
B.S. & 44.96 & 72.71 & 36.28 & 72.71 \\
C.P. & 15.28 & 69.22 & 12.97 & 69.87 \\
H.S. & 32.66 & 68.80 & 37.15 & 70.09 \\
Ha.S. & 55.68 & 41.35 & 58.27 & 46.44 \\
M.N. & 14.56 & 46.27 & 12.56 & 51.07 \\
L.J. & 15.84 & 52.10 & 19.75 & 60.57 \\
P.M. & 38.60 & 63.07 & 36.94 & 63.16 \\
P.H. & 59.78 & 80.69 & 60.32 & 80.63 \\
R.S. & 62.61 & 80.65 & 62.81 & 80.92 \\
S.C. & 41.82 & 56.30 & 41.43 & 56.21 \\
Mean & 38.18 & 63.13 & 37.85 & 65.17 \\
\hline
\end{tabular}

(1) (2) (3)

(1) and (2) $P<0.01$, (3) and (4) $P<0.01$. at the 90 per cent value of the total power was significantly higher $(P<0.004)$ and that at the 10 per cent value significantly lower than that of the single signals $(P<0.027$ for the upper and $P<0.004$ for the lower jaw tremor).

\section{Head deflected (Camper plane $+20^{\circ}$ )}

Head deflection influenced the shape of the power spectra in 9 out of 10 subjects. The group mean frequency corresponding to the 90 per cent value of the total power of the lower jaw decreased from 10.44 to $9.08 \mathrm{~Hz}(P>0.05)$, whereas that corresponding to the 10 per cent of the total power increased significantly from 2.79 to $4.14 \mathrm{~Hz}(P<0.05)$. The upper jaw tremor showed the same significant variations (Table 3). The power spectra of both tremors showed a spectral band between 5 and $8 \mathrm{~Hz}$ which was not consistently present in data obtained with the head upright (Fig. 3). 'This spectral band contained on average $63.13 / 65.17$ per cent of the lower/upper jaw tremor power vs the $38.18 / 37.85$ per cent with the 


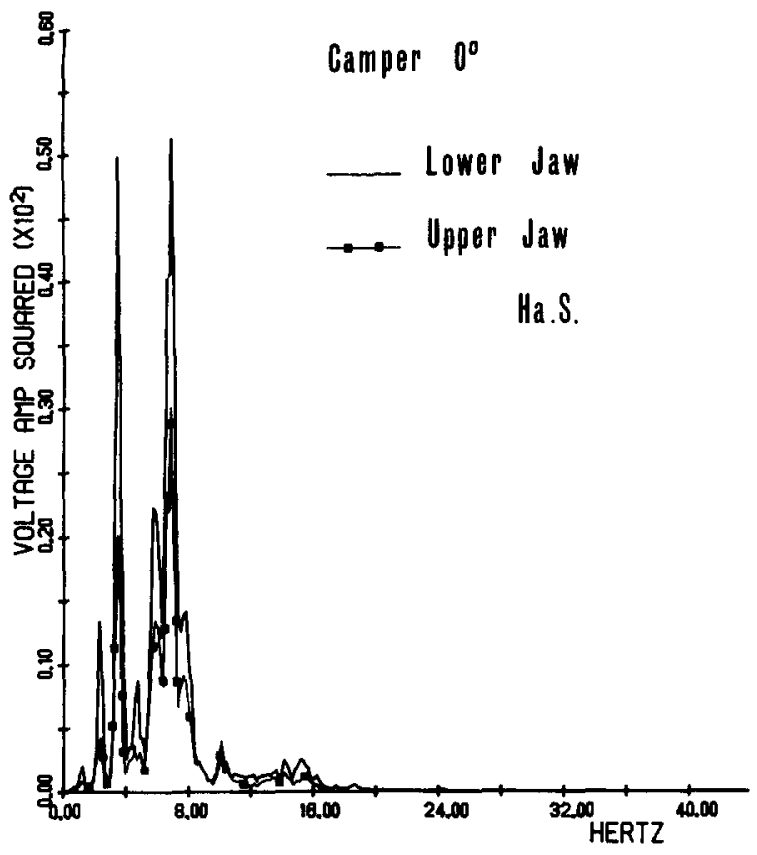

Fig. 2. Power spectra of the upper and lower jaw tremor with the head upright. Subject Ha.S.

Camper plane at $0^{\circ}$ (Table 5). The differences were statistically significant at the 0.01 level. Thus the jaw oscillated at a single frequency when the head was deflected.

Head deflection influenced the power spectral density of the differential signal in 4 out of 8 subjects. Three subjects had the power distributed in a smaller and the fourth in a wider frequency range than with the head upright. The other four subjects did not show clear changes.

\section{Head flexed (Camper plane $-20^{\circ}$ )}

Six subjects had power spectra with the same shape as that obtained with the head upright (Fig. 3). In the other 4 subjects, the power concentrated in the $4-12 \mathrm{~Hz}$ frequency range. Generally, head flexion shifted the power to a slightly higher frequency range. The frequency at the 50 per cent value of the total power of the lower jaw tremor increased significantly from 5.87 to $6.81 \mathrm{~Hz}$ and that of the upper one from 5.70 to $6.56 \mathrm{~Hz}(P<0.05$ for the lower and $P<0.01$ for the upper jaw tremor) (Tables 2 and 3 ).

The power spectra of the differential signal had, with two exceptions, a shape similar to that of the power spectra obtained with the head upright.

\section{Jaw tremor and ECG}

In all subjects, the following pattern recurred in the data (Fig. 4): waves of relative high amplitude and low frequency after each ECG-R-peak were followed by oscillations of decreasing amplitude and increasing frequency. The time relationship between the pattern of jaw tremor acceleration and heart activity was confirmed by the ECG-R-peak synchronous triggering of the acceleration signals on the oscilloscope screen. During an interval of approximately $0.4 \mathrm{~s}$ (in one subject $0.6 \mathrm{~s}$ ), following the ECG-R-peak with a
$0.2 \mathrm{~s}$ latency, successive waves had the same pattern, were in phase and varied only in amplitude. Thereafter the amplitude of the tremor signals decreased, the frequency increased and the waves were no longer in phase (Fig. 5).

\section{Electromyography}

The EMG-r.m.s. values (mean and confidence interval) for all the subjects are shown in Table 6 . No statistically significant differences were found between the mean values of the different muscles for the same head position and of the temporal muscles at different head positions $(P>0.05)$. The mean values of the masseter muscle differed significantly at different head positions $(P<0.05)$. The values obtained with the head tilted forwards were significantly smaller than those with the head backwards $(P<0.05)$.

\section{DISCUSSION}

Our results show that jaw tremor is a narrow-band low-frequency process, having on average 90 per cent of its power below $10.44 \mathrm{~Hz}$. Except for a preliminary report by Palla and Brown (1977), Körber's (1971a) study was the only one to consider the frequency of the jaw tremor at rest. According to Körber, the mandible at rest oscillates with frequencies between 5 and $12 \mathrm{~Hz}$ with harmonics up to $120 \mathrm{~Hz}$. However, a comparison with our findings is not possible because different methods were used. Previous research on the power spectral density of normal tremor has mainly studied finger and/or hand tremor, when these are held horizontally without any support (Randall and Stiles, 1964; Stiles and Randall, 1967; Wyatt, 1968; Randall, 1973; Rietz and Stiles, 1974; Elble and Randall, 1976). Our results show that the mean frequency at maximum power spectral density of jaw tremor is slightly lower than that of finger tremor, which according to Wyatt (1968), who used a similar method to ours is $6.44 \mathrm{~Hz}$. However, shape and frequency range of the power spectra, were markedly different, probably due to different mechanical characteristics of the two anatomical systems. The fact that finger tremor has a frequency range approximately 3 times larger than that of jaw tremor could be due also to differences in the low pass filtering of the acceleration signals.

The raw data of the lower and upper jaw acceleration had for all three head positions an almost identical pattern (Fig. 4), confirmed by the frequency analysis, which showed that the power spectral density of the lower and upper jaw were identical but for differences in the power. Although the lower jaw oscillated at the same frequency as the head, the acceleration was generally different. Cross-correlation techniques between the signals of both jaws (Bendat and Piersol, 1971, p. 25) could explain whether the lower jaw oscillates independently from the head.

The acceleration raw data and the ECG-R-peak triggered and superimposed acceleration signals showed, independently of the head position, a periodic pattern time related to the ECG-R-peak. These findings show that energy is present in the jaw and head tremor which is consistently related to the heart systole. Lynn and Yemm (1971), measuring the external forces required to move the mandible of relaxed 

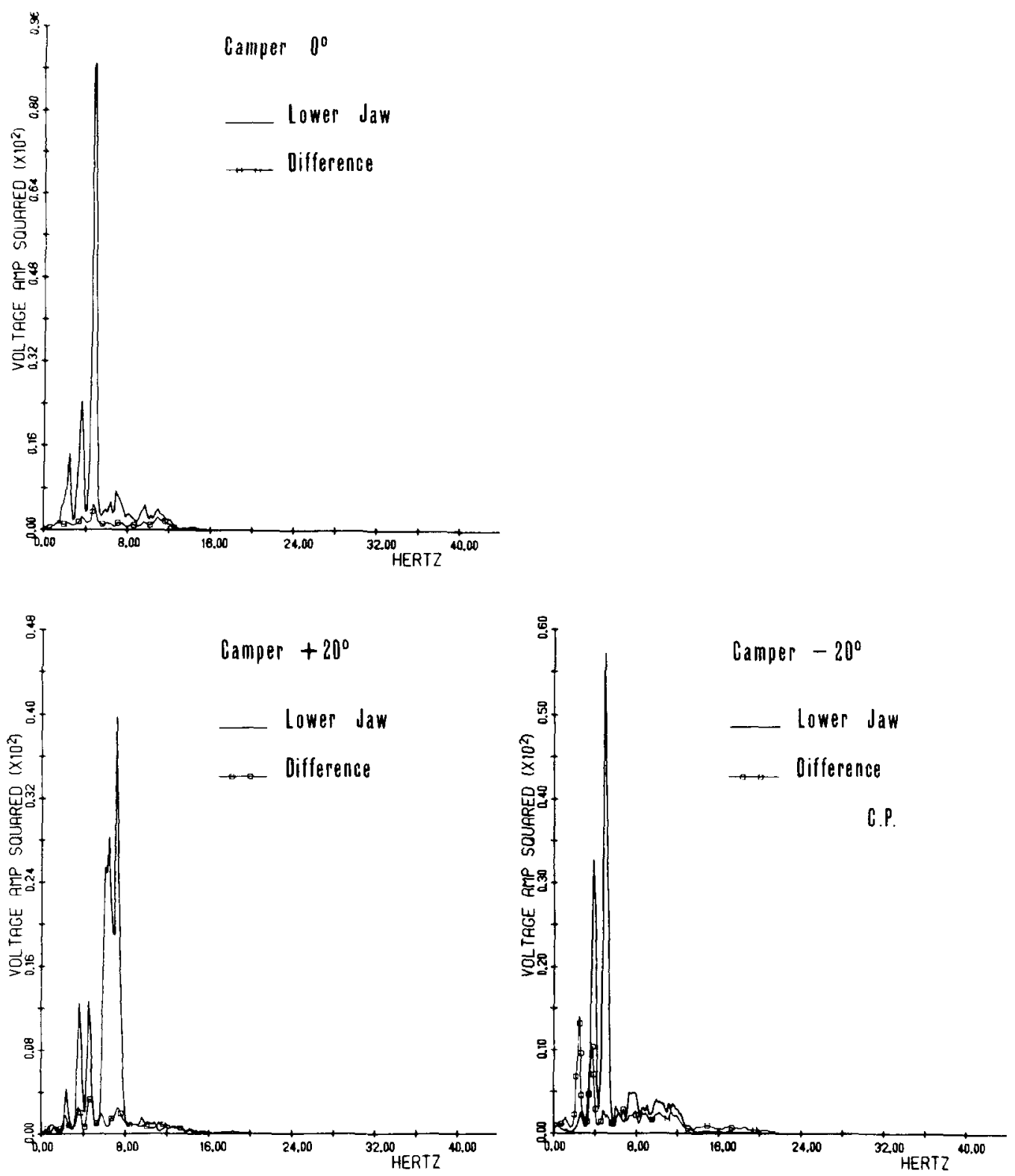

Fig. 3. Power spectra of the lower jaw tremor and of the differential signal with the head upright, deflected and flexed. Subject C.P.

subjects, registered a force variation in synchrony with the cardiac systole, which they assumed was due to the pulsation of the teeth in the socket. Our results show that those variations were more likely to be due to the oscillation of the jaws synchronously with the heart beat. A relationship between tremor and heart beat was shown by Brumlik (1962), Ozaki et al. (1962), Yap and Boshes (1967) and Carrie and Bickford (1969). Brumlik and Carrie and Bickford reported that the appearance in the tremor of energy related to cardiovascular activity was dependent upon the recording conditions. It is, therefore, possible that the absence of head fixation in our experiments favoured the appearance of the cardiac component of the tremor. Cardio-ballistic studies showed that each cardiac systole shakes the body (Scarborough et al., 1958; Starr, 1958; Brumlik, 1962). The tremor at rest that we found is possibly caused by damped ascillations in response to the shaking of the body caused by each heart beat. The cardiovascular-related pattern of the analogue tremor signals was present also with the head tilted backwards, a condition producing significant variations of the tremor power spectral density. Rietz and Stiles (1974) reported evidence that a visco-elastic-mass mechanism is at the basis of the normal tremor. They stated that "differences in the frequency and amplitude of the tremor may result from differences in such factors as the elastic element, muscle-limb geometry, neural-feedback and asynchrony of contraction of muscle fibers". As the mass and the muscle-limb geometry in our study was not affected by the head deflection, the changes in the power spectral density may have been caused by an increase in the elasticity of the soft tissues, i.e. by an increase of the muscle tonus (the spring constant of the visco-elastic-mass mechanism). Thus, the 


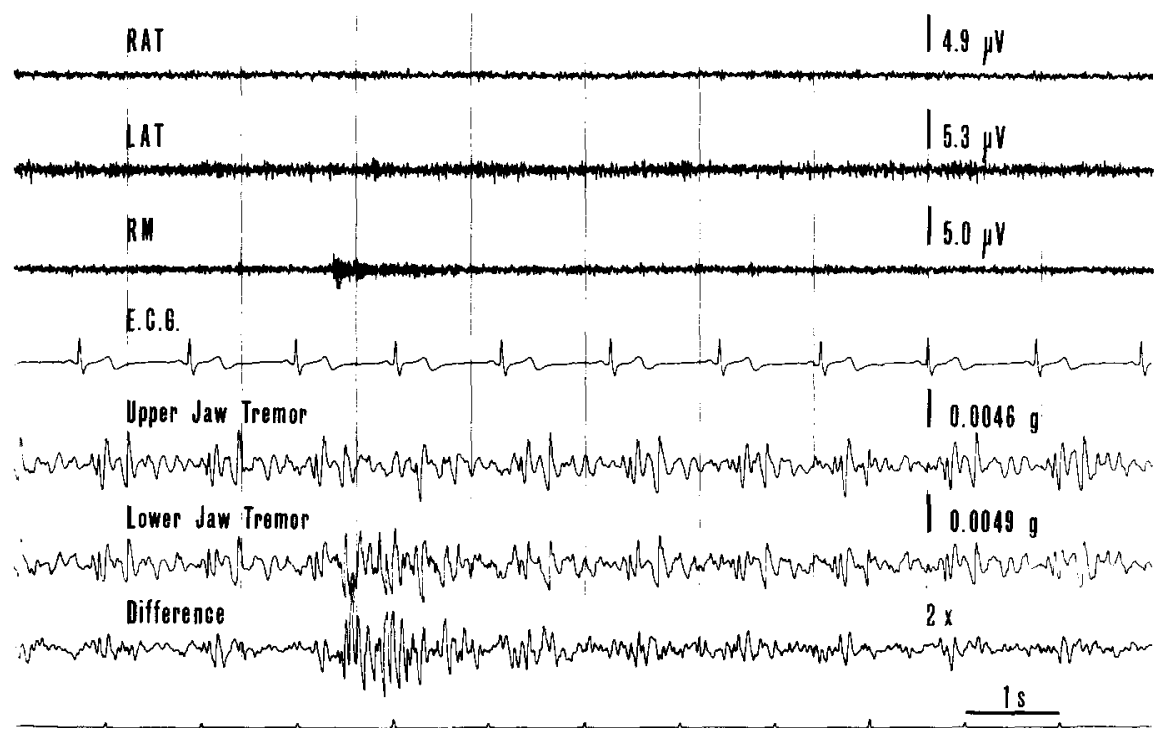

Fig. 4. Example of raw data. The upper three traces represent the electrical activity in the right (R.A.T.) left (L.A.T.) anterior temporal and right masseter (R.M.) muscles and the corresponding voltage in $\mu \mathrm{V}$. Note the increased frequency in the lower jaw tremor and differential signal and the loss of correlation with the ECG after a burst of activity in the right masseter. The differential signal was amplified 2 times.

muscle would act as a low-pass filter determining the frequency at which the lower jaw oscillates. The cardiac activity would then act as the motor which brings the system into oscillation. The fact that the EMG-r.m.s. values of the temporal and right masseter muscles did not increase significantly following the head deflection does not disprove this hypothesis. Indeed, it is likely that the head deflection mainly affected the supra- and infra-hyoid muscle group.
Failure to record a significant increase in the EMG-r.m.s. values in the muscles monitored may have been due to the insufficient sensitivity of EMGamplitude measurements to very small variations in the degree of neuromuscular activity, as a preliminary study on the EMG-frequency spectrum showed (S. Palla, unpublished). However, changes in the power spectral density of the lower jaw could be due only to the identical changes in the head tremor, in which
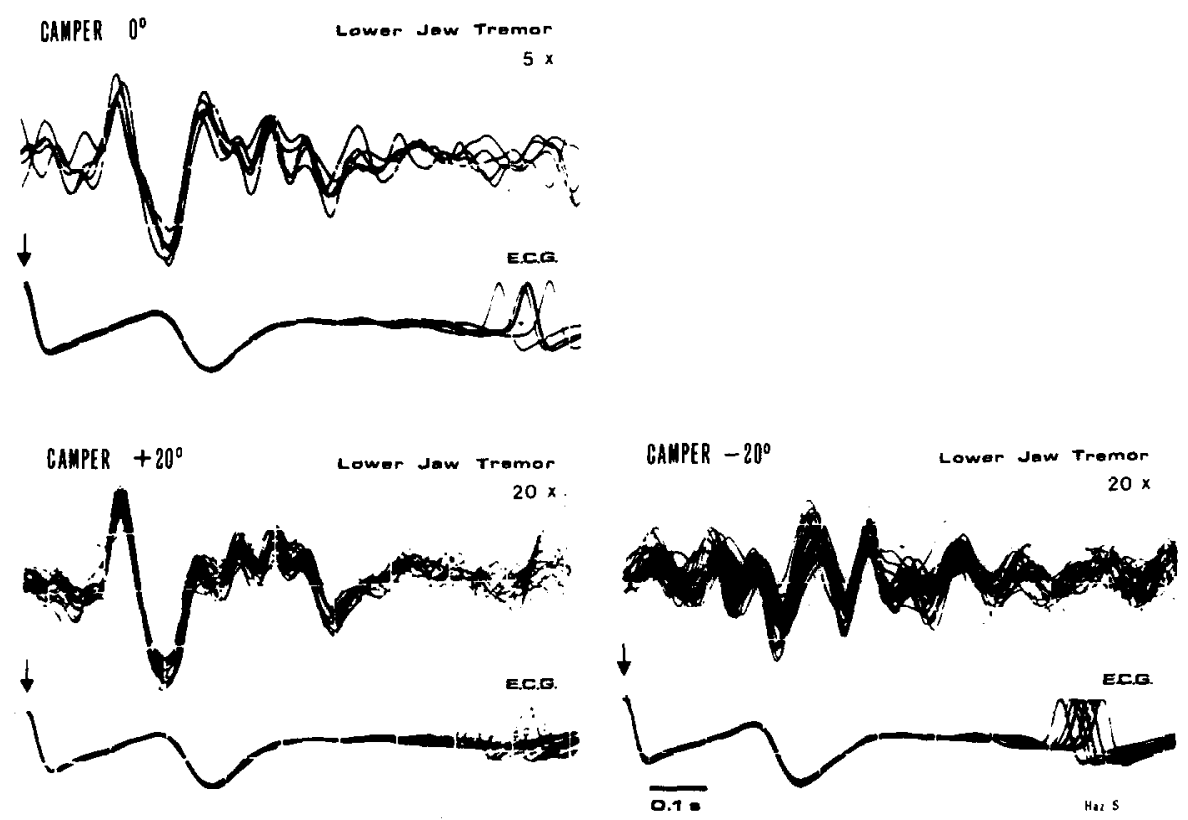

Fig. 5. Example of ECG-R-peak related superpositions of the lower jaw tremor. Superposition of 5 and 20 waves with the head upright, deflected and flexed. 
Table 6. Mean r.m.s.-voltage in $\mu \mathrm{V}$ and 95 per cent confidence interval of the electrical activity in the right and left anterior temporal and right masseter muscles with the head upright, deflected and flexed

\begin{tabular}{llll}
\hline \multicolumn{1}{c}{ Recordings } & $\begin{array}{c}\text { Right anterior } \\
\text { temporal }\end{array}$ & $\begin{array}{c}\text { Left anterior } \\
\text { temporal }\end{array}$ & Right masseter \\
\hline Head upright & $1.16 \pm 0.409^{*}$ & $1.14 \pm 0.283$ & $1.35 \pm 0.258$ \\
Head deflected & $1.13 \pm 0.378$ & $1.57 \pm 0.637^{*}$ & $1.68 \pm 0.552$ \\
Head flexed & $1.02 \pm 0.284$ & $1.68 \pm 0.120^{*}$ & $1.17 \pm 0.273$ \\
\hline
\end{tabular}

* 9 subjects tested.

case the muscles responsible for the head posture would have acted as the low pass filter. Cross-correlation techniques are needed to solve this problem.

The tremor power spectral density obtained with the head flexed was not significantly different from that obtained with the head upright. Solow and Tallgren (1971) showed that in the natural balanced position the head is slightly tilted forwards. The head flexion in our study was probably within the range of the natural head position, and therefore did not change the muscle tone and the shape of the power spectra.

Körber (1971b) reported that each tooth oscillates in its socket synchronously with the pulse with an amplitude of on the average $0.4 \mu \mathrm{m}$, and a maximum of about $12 \mu \mathrm{m}$ in the case of loose teeth. Recordings with an accelerometer taped to the forehead showed the same ECG-related pattern. These signals had the same power spectral density as those with the acclerometers cemented to the upper premolars, showing that the cardiac-related tremor pattern was not due to the oscillation of the teeth in their sockets. Furthermore. the amplitude of the movement of the premolars synchronous with the pulse was probably argely reduced by cementing the accelerometers to at least two teeth.

Acknowledgements-We wish to thank Mr. G. Brown for developing the computer program for the frequency analysis, Mr. D. Geister, Research Scientist, for his help in the design of the data acquisition system and Dr. F. Bosman for his helpful suggestions in the interpretation of the power spectra. This work was supported by U.S. Public Health Department Grant DE 02731-12.

\section{REFERENCES}

Bando E., Fukushima S. Kawabata H. and Kohno S. 1972. Continuous observations of mandibular positions by telemetry. $J$. prosth. Dent. 28, 485-490.

Bendat J. S. and Piersol A. G. 1971, Random Data: Analysis and Measurement Procedures. Wiley-Interscience, New York.

Brown G. S. 1975. The fidelity of digital recordings. A framework for future decisions. M.S. Thesis. The University of Michigan.

Brown G. S., Altug S. S., McCall W. D. and Geister D. E. 1979. Software support for computerized electromyography in clinical dentistry. IEEE Trans. biomed. Engng. 26, 357-365.

Brumlik J. 1962. On the nature of normal tremor. Neurology 12, 159-179.

Carrie J. R. G. and Bickford R. G. 1969. Cardiovascular factors in limb tremor. Neurology 19, 116-127.
Elble R. J. and Randall J. E. 1976. Motor-unit activity responsible for 8 to $12 \mathrm{~Hz}$ component of human physiological finger tremor. J. Neurophysiol. 39, 370-383.

Gamick J. and Ramfjord S. P. 1962. Rest position. J. prosth. Dent. 895-911.

Geister D. E., McCall W. D. and Ash M. M. 1975. Computerized data acquisition and analysis for real-time electromyography in clinical dentistry. Proc. IEEE 63. $1404-\$ 414$.

Griffiths M. J. 1975. Telemetry and the study of vertical jaw relations, $J$. Dent. 3, 261-266.

Harding L. 1976. Numerical analysis and applications software abstracts. Computing Center Memo 341 2nd Edn. University of Michigan. Computing Center, Ann Arbor, Mich.

Helkimo M. 1974. Studies on function and dysfunction of the masticatory system. II. Index for anamnestic and clinical dysfunction and occlusal state. Swed. dent. J. 67. $101-119$

Joniot B. 1974. Physiologic mandibular resting posture, J. prosth. Dent. 31, 4-9.

Körber K. H. 1971a. Electronische Regiestrierung der Unterkieferbewegungen im normalen und okklusionsgestoerten Gebiss. Dt. zahnärztl. Z. 26, 167-176.

Körber K. H. 1971b. Electronic registration of tooth movements. Int. dent. J., Lond. 21, 466-477.

Lippold O. C. J., Redfearn J. W. T. and Vuco J. 1957. The rhythmical activity of groups of motor units in the voluntary contraction of muscles. $J$. Physiol. Lond. 137, $473-487$.

Lippold O. C. J. 1970. Oscillation in the stretch reflex arc and the origin of the rhythmical, 8-12 c/s component of physiological tremor. $J$. Physiol, Lond. 206, 359382.

Lous I,, Sheikoleslam A. and Møller E. 1970. Postural activity in subjects with functional disorders of the chewing apparatus. Scand. J. dent. Res. 78, 404-410.

Lund P., Nishiyama T. and Møller E. 1970. Postural activity in the muscles of mastication with subject upright, inclined. and supine. Scand. I. dent. Res. 78, $417-424$.

Lynn A. M. J. and Yemm R. 1971. External forces required 10 move the mandible of relaxed human subjects. Archs oral Biol. 16, 1443-1447.

Mercer D. M. A. 1958. The application of correlation techniques in noise analysis. Ann. occup. Hvg. 1, 81-89.

Moller E. 1966. The chewing apparatus. An electromyographic study of the action of the muscles of mastication and its correlation to facial morphology. Acia physiol. scand. 69. Suppl. 280.

Moller E., Sheikoleslam A. and Lous 1. 1971. Deliberate relaxation of the temporal and masseter muscles in subjects with functional disorders of the ehewing apparatus. Scand. J. dent. Res. 79, 478-482.

Ozaki T., Sato K., Awazu T., Mimura K., Honda N., Teramoto S. and Kitajima K. 1962. Some observations on minor tremors related to heart beat. Jap. J. Physiol. 12 , 484-493.

Palla S. and Brown G. S. 1977. Das Frequenzspektrum 
des Unterkiefertremors. Schweiz, Mschr, Zahnheilk. 87, 1119-1133.

Randall J. E. and Stiles R. N. 1964. Power spectral analysis of finger acceleration tremor. J. appl. Physiol. 19, $357-360$.

Randall J. E. 1973. A stochastic time series model for hand tremor. J. appl. Physiol. 34, 390-395.

Rietz R. R. and Stiles R. N. 1974. A viscoelastic-mass mechanism as a basis for normal postural tremor. $J$. appl. Physiol. 37, 852-860.

Scarborough W. R., Folk E. F., Smith P. M. and Condon J. H. 1958. The nature of records from ultra-low frequency ballistocardiographic systems and their relation to circulatory events. Am. J. Cardiol. 2, 613-641.

Siegel S. 1956. Nonparametric Statistics for the Behavioral Sciences. McGraw-Hill, New York.

Solow B. and Tallgren A. 1971. Natural head position in standing subjects. Acta odont. scand. 29, 591-607.

Starr I. 1958. On reading ballistocardiograms. Am. J. Cardiol. 2, 404-416.
Stiles R. N. and Randall J. E. 1967. Mechanical factors in human tremor frequency. J. appl. Physiol. 23, 324-330. Wyatt R. H. 1968. A study of power spectra analysis of normal finger tremors. IEEE Trans. biomed. Engng 15, $33-45$.

Wyke B. D. 1974. Neuromuscular mechanisms influencing mandibular posture: a neurologist's review of current concepts. J. Dent. 2, 111-120

Yap C. B. and Boshes B. 1967. The frequency and pattern of normal tremor. Electroenceph. clin. Neurophysiol. 22, 197-203.

Yemm R. and Berry D. C. 1969. Passive control in mandibular rest position. J. prosth. Dent. 22, 30-36.

Yemm R. and Nordstrom S. H. 1974. Forces developed by tissue elasticity as a determinant of mandibular resting posture in the rat. Archs oral Biol. 19, 347-351.

Yemm R. 1976. The role of tissue elasticity in the control of mandibular resting posture. In: Mastication (Edited by Anderson D. J. and Matthews B.). Wright \& Sons, Bristol. 